\title{
The heterologous expression of Escherichia coli MutT enzyme is involved in the protection against oxidative stress in Leishmania braziliensis
}

\author{
Laila de Carvalho Andrade', Ana Maria Murta Santi', Ceres Luciana Alves², \\ Wesley Roger Rodrigues Ferreira ${ }^{2}$, Antônio Vinícius de Assis ${ }^{2}$, Edward Oliveira', \\ Carlos Renato Machado ${ }^{2}+$, Silvane Maria Fonseca Murta ${ }^{1 /+}$ \\ ${ }^{1}$ Fundação Oswaldo Cruz-Fiocruz, Instituto René Rachou, Belo Horizonte, MG, Brasil \\ ${ }^{2}$ Universidade Federal de Minas Gerais, Instituto de Ciências Biológicas, Departamento de Bioquímica e Imunologia, \\ Belo Horizonte, MG, Brasil
}

\begin{abstract}
BACKGROUND Oxidative stress is responsible for generating DNA lesions and the 8-oxoguanine (8-oxoG) is the most commonly lesion found in DNA damage. When this base is incorporated during DNA replication, it could generate double-strand DNA breaks and cellular death. MutT enzyme hydrolyzes the 8-oxoG from the nucleotide pool, preventing its incorporation during DNA replication.
\end{abstract}

\begin{abstract}
OBJECTIVES To investigate the importance of 8-oxoG in Leishmania infantum and L. braziliensis, in this study we analysed the impact of heterologous expression of Escherichia coli MutT (EcMutT) enzyme in drug-resistance phenotype and defense against oxidative stress.

METHODS Comparative analysis of L. braziliensis and L. infantum $\mathrm{H}_{2} \mathrm{O}_{2}$ tolerance and cell cycle profile were performed. Lines of L. braziliensis and L. infantum expressing EcMutT were generated and evaluated using susceptibility tests to $\mathrm{H}_{2} \mathrm{O}_{2}$ and $\mathrm{Sb}^{\amalg I I}$, cell cycle analysis, $\gamma \mathrm{H} 2 \mathrm{~A}$ western blotting, and BrdU native detection assay.

FINDINGS Comparative analysis of tolerance to oxidative stress generated by $\mathrm{H}_{2} \mathrm{O}_{2}$ showed that L. infantum is more tolerant to exogenous $\mathrm{H}_{2} \mathrm{O}_{2}$ than L. braziliensis. In addition, cell cycle analysis showed that L. infantum, after treatment with $\mathrm{H}_{2} \mathrm{O}_{2}$, remains in $\mathrm{G} 1$ phase, returning to its normal growth rate after $72 \mathrm{~h}$. In contrast, after treatment with $\mathrm{H}_{2} \mathrm{O}_{2}, L$. braziliensis parasites continue to move to the next stages of the cell cycle. Expression of the E. coli MutT gene in L. braziliensis and $L$. infantum does not interfere in parasite growth or in susceptibility to $\mathrm{Sb}^{\mathrm{III}}$. Interestingly, we observed that L. braziliensis EcMutTexpressing clones were more tolerant to $\mathrm{H}_{2} \mathrm{O}_{2}$ treatment, presented lower activation of $\gamma \mathrm{H} 2 \mathrm{~A}$, a biomarker of genotoxic stress, and lower replication stress than its parental non-transfected parasites. In contrast, the EcMutT is not involved in protection against oxidative stress generated by $\mathrm{H}_{2} \mathrm{O}_{2}$ in L. infantum.
\end{abstract}

MAIN CONCLUSIONS Our results showed that 8-oxoG clearance in L. braziliensis is important to avoid misincorporation during DNA replication after oxidative stress generated by $\mathrm{H}_{2} \mathrm{O}_{2}$.

Key words: Leishmania braziliensis - Leishmania infantum - MutT - DNA repair - 8-oxoG - oxidative stress

Leishmaniasis refers to a spectrum of diseases caused by protozoan Leishmania parasites. It is a neglected tropical disease and represents one of the major public health problems in developing countries of the Indian subcontinent, South-East Asia, Latin America and East Africa according to World Health Organization. ${ }^{(1)}$ Human leishmaniasis has a prevalence of 12 million cases and an incidence of 1.2 million new cases annually, with an estimated population of 350 million at risk. ${ }^{(2)}$ Depending on genetic and environmental factors, the host immune

doi: 10.1590/0074-02760190469

Financial support: CNPq, FAPEMIG (CBB-PPM 610/15), INOVA FIOCRUZ and CAPES

EO, CRM and SMFM are research fellows supported by CNPq. LCA and AMMS are research fellows supported by CAPES.

+ Corresponding authors: silvane.murta@fiocruz.br / crmachad@icb.ufmg.br

(1) http://orcid.org/0000-0002-8523-2155

(1) http://orcid.org/0000-0002-8724-3165

Received 10 December 2019

Accepted 02 June 2020 response and mainly on Leishmania species involved, the disease can comprise two main clinical forms: visceral leishmaniasis or cutaneous leishmaniasis. In the New World, L. (Viannia) braziliensis is the causative agent of cutaneous and mucocutaneous leishmaniasis, whereas $L$. (Leishmania) infantum (syn. L. (L.) chagasi) causes visceral leishmaniasis, which is lethal if not treated. ${ }^{(3)}$

In the absence of an efficient vaccine for human, the control of leishmaniasis relies primarily on chemotherapy. Pentavalent antimony-containing compounds such as sodium stibogluconate $\left(\right.$ Pentostam ${ }^{\circledR}$ ) and N-methylglucamine $\left(\right.$ Glucantime $^{\circledR}$ ) have been used as first-line therapies against all forms of leishmaniasis. The mechanisms of action of antimony are not entirely clear. It is generally agreed that trivalent antimony $\left(\mathrm{Sb}^{\mathrm{III}}\right)$ is the active form of the drug against amastigote and promastigote forms of Leishmania. ${ }^{(4)}$ Some studies have suggested that antimony inhibits macromolecule biosynthesis in amastigotes, possibly via inhibition of glycolysis and fatty acid oxidation. ${ }^{(5)}$ Earlier report has indicated that antimonials cause perturbations in the thiol redox po- 
tential, which would drive to parasite death by oxidative stress. ${ }^{(6)}$ Trypanosomatids are constantly exposed to different reactive oxygen species (ROS), such as superoxide anion, hydrogen peroxide and hydroxyl radicals, formed during the host defense reaction, either by exogenous (chemotherapeutic) or endogenous action (metabolism of the parasite itself or inflammatory cytokines). The action of ROS can lead to deleterious damage to DNA of the parasite and hence its death. Thus, an effective antioxidant defense system, which can prevent and repairing the damage caused by oxidising agents, is essential for the survival of the parasite inside parasitophorous vacuoles in human macrophages.

Oxidation represents the main endogenous factor of DNA damage, which can cause genomic instability and cell death. Due to its low redox potential, guanine $(\mathrm{G})$ is the most vulnerable base to ROS oxidation. ${ }^{(7)}$ The main product of $\mathrm{G}$ oxidation is 7,8-dihydro-8-oxoguanine (8-oxoG). ${ }^{(8)}$ If not repaired during DNA replication, 8-oxoG can pair with adenine and cause a G:C to T:A transversion. During the DNA repair of 8-oxoG, doublestrand breaks could be generated, which can be highly deleterious. ${ }^{(9)}$ Due to its high ability to cause lesions in the DNA, 8-oxoG is used as a cellular biomarker of oxidative stress. ${ }^{(10)}$

The GO-system is a three-component 8-oxoG repair pathway compost by genes MutT, MutY and MutM in bacteria and MTH1, MUTYH and OGG1 in humans, respectively. ${ }^{(11)}$ The enzyme MutT (or MTH1), focus of our study, hydrolyzes 8-oxo-dGTP in the nucleotide pool, returning it to the monophosphate form. ${ }^{(12)}$ The enzymes MutM (or OGG1) and MutY (MUTYH) are responsible for repairing 8-oxoG paired with cytosine in the DNA or removing the adenine in the 8-oxoG:A mispair, respectively. ${ }^{(7,8)}$

The MutT enzyme gene from Escherichia coli (NCBI: P08337) has $390 \mathrm{bp}$ and encodes a protein with 129 amino acids. It belongs to the superfamily of Nudix Hydrolases (Nucleosides Diphosphates attached to other moieties, $\mathrm{X}$ ). This superfamily contains a sequence called $\mathrm{Nu}$ dix Box with a conserved 23-amino acid sequence GX${ }_{5} \mathrm{EX}_{7} \mathrm{REUXEEXGU}$, where $\mathrm{X}$ can be any residue and $\mathrm{U}$ is a hydrophobic residue. ${ }^{(13)}$

The leishmanial genomic project identified several DNA repair pathway genes in parasite genome..$^{(14,15)}$ However, some important elements of the DNA repair machinery, such as a MutT homolog, have not yet been characterised. The complete sequence of the MutT gene in Leishmania spp. is available in database (TritrypDB). It is present in 13 different species of Leishmania as $L$. braziliensis, L. infantum, L. major, L. aethiopica, L. donovani, L. mexicana, L. tarentolae, L enriettii, L. gerbii, $L$. arabica, $L$. panamensis, L. tropica and L. turanica (TritrypDB). However, the role of the MutT enzyme in Leishmania has not been described yet.

In this study, we analyse the tolerance of $L$. braziliensis and $L$. infantum parasites to oxidative stress generated by $\mathrm{H}_{2} \mathrm{O}_{2}$ and compare their cell cycle after $\mathrm{H}_{2} \mathrm{O}_{2}$ treatment. In order to investigate the importance of 8-oxoG to oxidative stress we generated $L$. braziliensis and L. infantum parasites heterologously expressing E. coli MutT, since the role of this enzyme was well established. We analysed the phenotype these parasites in relation to growth in culture medium, tolerance to oxidative stress generated by $\mathrm{H}_{2} \mathrm{O}_{2}$, susceptibility to $\mathrm{Sb}^{\mathrm{III}}$, cell cycle progression, DNA damage and replication stress generation.

\section{MATERIALS AND METHODS}

Leishmania spp. samples - Promastigote forms of $L$. (Viannia) braziliensis (MHOM/BR/75/M2904) and $L$. (Leishmania) infantum (syn. L. (L.) chagasi) (MCAN/ $\mathrm{BR} / 2000 / \mathrm{BH} 400$ ) were used in this study. Parasites were grown at $26^{\circ} \mathrm{C}$ in 199 medium (M199) supplemented with $2 \mathrm{mM}$ L-glutamine, $5 \mu \mathrm{g} / \mathrm{mL}$ hemin, $50 \mu \mathrm{g} /$ $\mathrm{mL}$ streptomycin, $2 \mu \mathrm{g} / \mathrm{mL}$ biopterin, $1 \mu \mathrm{g} / \mathrm{mL}$ biotin, $40 \mathrm{mM}$ HEPES $\mathrm{pH} 7.4,500 \mathrm{U}$ penicillin and $10 \% \mathrm{v} / \mathrm{v}$ heat-inactivated fetal calf serum. ${ }^{(16)}$ These parasites were harvested in the logarithmic growth phase washed in phosphate buffered saline (PBS) (137 mM NaCl, $2.7 \mathrm{mM}$ $\mathrm{KCl}, 10 \mathrm{mM} \mathrm{Na}_{2} \mathrm{HPO}_{4}$ and $2 \mathrm{mM} \mathrm{KH}_{2} \mathrm{PO}_{4}$ ) and the parasitic pellets were used for DNA and RNA preparations.

Generation of E. coli mutT expressing L. braziliensis and L. infantum lines - A $390 \mathrm{bp}$ fragment corresponding to $E$. coli mutT encoding region (NCBI accession number: P08337) was amplified with $P f x$ DNA polymerase (Invitrogen, Life technologies, CA, USA) from AB1157 E. coli genomic DNA using the forward primer: 5'-tAGATCTccaccATGAAAAAGCTGCAAATTGC-3, and the reverse primer: 5'-ttAGATCTCTACAGACGCTTAAGCTTCGCA-3'. The lower case letters indicate the Kosak sequence and the underlined sequences correspond to $B g l$ II restriction site. The obtained polymerase chain reaction (PCR) products were cloned into the pGEM-T Easy $^{\circledR}$ vector (Promega, Madison, WI, USA) and subsequently submitted to sequencing reaction for confirmation of correct sequence. All constructs were sequenced in an ABI 3130 (Applied Biosystems, Foster City, CA, USA). The pGEM-EcmutT constructs were restricted with $B g l I I$ and the fragments released were subcloned into the dephosphorylated pIR1BSD expression vector (kindly provided by Dr Stephen Beverley, Washington University, USA). To confirm the correct direction of cloning, the constructs were then digested with HindIII and EcoRI separated releasing fragments that confirmed the sense direction of the EcmutT gene. Thus, the constructs pIR1BSD (empty vector), and pIR1BSD-EcmutT were linearised by $S w a \mathrm{I}$ digestion and electroporated into wild-type $L$. braziliensis and $L$. infantum lines using a Gene Pulser XCell electroporation system (Bio-Rad, Hercules, CA, USA) according to the protocol described by Robinson and Beverley. ${ }^{(17)}$ This stable transfection allowed integration of the pIR1 vector into the rDNA $18 \mathrm{~S}$ ribosomal small subunit locus of the parasite. ${ }^{(17)}$ Colonies were obtained following plating on semisolid M199 containing blasticidin (BSD) $(10 \mu \mathrm{g} / \mathrm{mL})$. After 1-2 weeks, clonal lines were selected, and the presence of constructs was confirmed by PCR tests using genomic DNA with specific primers for the BSD marker.

$R N A$ purification and reverse transcription-PCR (RT$P C R)$ - Leishmania spp. total RNA purification was performed from $10^{8}$ promastigotes using TRIzol (Invitrogen) 
reagent and treated with DNAse (Invitrogen) for DNA contaminant removal according to the manufacturer's instructions. The purified RNA was then used in a cDNA synthesis reaction with $500 \mathrm{ng}$ oligo $\mathrm{d}(\mathrm{T})_{12-18}$, using the Superscript III first-strand synthesis system for RT-PCR (Invitrogen). The subsequent EcmutT fragment specific amplification was performed using the following primers 5'-GAATTCCCGGACAGGCATATAA-3' (forward) and 5'-CATTAAGACCGACTAGCGACATC-3' (reverse). The control of RT-PCR was processed in the same conditions as the samples but without reverse transcriptase enzyme. The DNA polymerase I alpha catalytic subunit constitutive gene from L. braziliensis (LbrM.16.1600) was used to normalise the amount of sample analysed. A fragment of $69 \mathrm{bp}$ of the DNA polymerase I gene was amplified according described by Moreira et al ${ }^{(18)}$ Both pair of primers EcmutT and DNA polymerase I amplified fragments of 115 and $69 \mathrm{bp}$ respectively, in all Leishmania samples analysed. PCR was carried out in a final volume of 20 $\mu \mathrm{L}$ of reaction mixture containing 10 pmol of forward and reverse primers, $1 \mathrm{x}$ Supermix High Fidelity reaction mix (Invitrogen) and $10 \mathrm{ng}$ of template cDNA. The PCR conditions were as follows: an initial denaturation step at $95^{\circ} \mathrm{C}$ for $5 \mathrm{~min}$ followed by 30 cycles of denaturation at $95^{\circ} \mathrm{C}$ for $30 \mathrm{~s}$, annealing at $60^{\circ} \mathrm{C}$ for $30 \mathrm{~s}$ and extension at $72^{\circ} \mathrm{C}$ for $30 \mathrm{~s}$. Following amplification, $6 \mu \mathrm{L}$ of each PCR product was electrophoresed in a $6 \%$ polyacrylamide gel and silver stained.

Susceptibility assays of L. braziliensis and L. infantum clonal lines to $\mathrm{Sb}^{\text {III }}$ and $\mathrm{H}_{2} \mathrm{O}_{2}$ - Promastigotes of wildtype $L$. braziliensis and $L$. infantum clonal lines nontransfected or transfected with the constructs pIR1BSD (empty vector) or pIR1BSD-EcmutT were submitted to $\mathrm{Sb}^{\text {III }}$ (Sigma-Aldrich, St. Louis, MO, USA) susceptibility tests. Parasites were incubated in M199 medium at $2 \mathrm{x}$ $10^{6}$ cells $/ \mathrm{mL}$ into 24 -well plates in the absence or presence of several concentrations of $\mathrm{Sb}^{\mathrm{III}}(0.3$ to $149.9 \mu \mathrm{M})$ for $48 \mathrm{~h}$ that correspond to log phase of growth. The effective concentration required to decrease growth by $50 \%\left(\mathrm{EC}_{50}\right)$ was determined using a model $\mathrm{Z} 1$ Coulter Counter (Beckman Coulter, Fullerton, CA, USA). EC $_{50}$ values were determined from at least three independent measurements performed in triplicate, using the linear interpolation method. ${ }^{(19)}$

To test the survival to $\mathrm{H}_{2} \mathrm{O}_{2}$ (Sigma-Aldrich), parasites were incubated in PBS at $2 \times 10^{6}$ cells $/ \mathrm{mL}$ into $15 \mathrm{~mL}$ tubes in the absence or presence of different concentrations of $\mathrm{H}_{2} \mathrm{O}_{2}(100$ to $700 \mu \mathrm{M})$ for $20 \mathrm{~min}$ at $26^{\circ} \mathrm{C}$. Subsequently the parasites were washed in PBS and incubated in M199 medium. The survival rate of the cultures was determined by counting the number of live parasites during 4, 24, 48, 72, 96, 120, 144 and $168 \mathrm{~h}$ of growth after exposure to $\mathrm{H}_{2} \mathrm{O}_{2}$. The parasite number was determined in a cytometry chamber using the erythrosine vital stain to differentiate living and dead cells. In addition, the parasite number was also determined using a model Z1 Coulter Counter (Beckman Coulter) and at least three independent measurements were performed in triplicate.

Cell cycle analysis - In order to investigate the effect of $\mathrm{H}_{2} \mathrm{O}_{2}$ treatment on the cell cycle of nontransfected and transfected parasites with the EcmutT gene, these parasites incubated in PBS containing $350 \mu \mathrm{M} \mathrm{H}_{2} \mathrm{O}_{2}$ for $20 \mathrm{~min}$ at $26^{\circ} \mathrm{C}$, washed in PBS and incubated in M199 medium during 24 and $72 \mathrm{~h}$. It is important to remove the $\mathrm{H}_{2} \mathrm{O}_{2}$ from medium, since that it may to generate others components which may oxide in the medium. Subsequently, the parasites were washed once with PBS, fixed overnight in $70 \%$ ethanol $(\mathrm{v} / \mathrm{v})$ and incubated at $37^{\circ} \mathrm{C}$ for $30 \mathrm{~min}$ in a PBS solution containing $10 \mu \mathrm{g} / \mathrm{mL}$ of propidium iodide (PI) and RNAse A (Invitrogen). The DNA content of PI-incorporated cells was analysed in a FACScan flow cytometer (Becton Dickinson Biosystems) using FloJo-V10 ${ }^{\mathrm{TM}}$ software. Each experiment was performed at least three times in triplicate.

Activation percentage of gammaH2A by Western blotting - For Western blotting assays, exponentially grown $L$. braziliensis and $L$. infantum promastigotes were incubated in PBS containing $350 \mu \mathrm{M} \mathrm{H}_{2} \mathrm{O}_{2}$ for $20 \mathrm{~min}$, washed in PBS and incubated in M199 medium during $30 \mathrm{~min}$ and $4 \mathrm{~h}$ and then submitted to protein extraction. Cells were washed and resuspended in sodium dodecyl sulphate (SDS) gel-loading buffer $[100 \mathrm{mM}$ Tris- $\mathrm{HCl}(\mathrm{pH}$ 6.8), $200 \mathrm{mM}$ dithiothreitol, $4 \%$ SDS, $0.2 \%$ bromophenol blue, $20 \%$ glycerol], and boiled for $10 \mathrm{~min}$, generating total extract. Proteins were separated on a $15 \%$ SDS polyacrylamide gel, blotted $(1 \mathrm{~h}, 300 \mathrm{~mA})$ onto nitrocellulose membranes, and incubated with rabbit polyclonal anti- $\gamma \mathrm{H} 2 \mathrm{~A}(1: 3,000)$ (kindly provided by Dr Richard McCulloch's lab) or mouse monoclonal anti-alpha-tubulin $(1: 5,000)$ (Abcam, Cambridge, UK) antibodies, during 12 $\mathrm{h}$ at $4^{\circ} \mathrm{C}$ in the blocking solution. The blots were washed twice and incubated with horseradish peroxidase-conjugated anti-rabbit or anti-mouse IgG antibodies $(1: 5,000)$ (GE Healthcare) for $1 \mathrm{~h}$ at room temperature. After incubation, the membranes were washed, incubated with ECL Plus chemiluminescent substrate (GE Healthcare) and revealed by ImageQuant LAS 4000 (GE Healthcare). The intensity of the bands was analysed using the software GelAnalyzer 2010 (gelanalyzer.com).

Analysis of replication stress through the BrdU native detection assay - For detection of long fragments of single strand DNA (ssDNA), characteristics of replication stress, exponentially growing promastigote parasites were incubated in PBS containing $350 \mu \mathrm{M} \mathrm{H}_{2} \mathrm{O}_{2}$ and 100 $\mu \mathrm{M}$ of 5-bromo-2'-deoxyuridine (BrdU) for $1 \mathrm{~h}$ to allow its incorporation into DNA. Thus, all the samples were harvested by centrifugation $(3000 \mathrm{~g}, 5 \mathrm{~min})$, washed using PBS, and fixed using $4 \%$ paraformaldehyde diluted in PBS for $10 \mathrm{~min}$ at room temperature. Parasite cells were then deposited and spread out onto slides pre-treated with $0.1 \%$ poly-L-lysine. Next, parasites cells were washed with PBS, and permeabilised with $0.2 \%$ Triton $\mathrm{X}-100$ for $10 \mathrm{~min}$ at room temperature. To ensure all cells incorporated BrdU, aliquots of each sample analysed were subjected to DNA denaturation using $2.5 \mathrm{M}$ $\mathrm{HCl}$ for $20 \mathrm{~min}$. Then, all samples were washed and BrdU was detected (when accessible) using $\alpha$-BrdU-rat antibody (Abcam) diluted 1:250 in blocking solution [3\% bovine serum albumin (BSA) (w/v) in PBS] for 3 $\mathrm{h}$ at room temperature, followed by incubation for more 
$1 \mathrm{~h}$ with Alexa Fluor 555-conjugated anti-rat antibody (Thermo Scientific) diluted 1:1,000 in blocking solution. After that, the slides-containing-cells were washed repeatedly (three times) with PBS. ProLong ${ }^{\circledR}$ Diamond Antifade Mountant with DAPI (Life Technologies) was used to be anti-fade mounting solution and to stain organelles containing DNA (i.e., nucleus and kinetoplast). For these experiments, images were captured using Axio Imager fluorescence microscope coupled with a digital camera (Axiocam 503 mono), and were analysed using Zen software 2.6 (blue edition). The measurement of the parasites showing presence of ssDNA foci was made using ImageJ software (NIH, version $1.47 \mathrm{t})$.

Statistical analysis - The statistical analysis were performed using the GraphPad Prism 5.0 program (GraphPad Software Inc., CA, USA). All experiments were performed at least three times and data have been represented as mean \pm standard deviation (SD). Results were analysed for significant differences using analysis of variance (ANOVA) or Student's $t$ test. A $\mathrm{p}$ value of less than 0.05 was considered statistically significant.

\section{RESULTS}

Comparative analysis of L. braziliensis and L. infantum $\mathrm{H}_{2} \mathrm{O}_{2}$ tolerance - Comparative analysis of tolerance to oxidative stress generated by increased concentration of hydrogen peroxide was evaluated between $L$. braziliensis and L. infantum wild-type species (Fig. 1). Firstly, we evaluated the susceptibility these parasites after $48 \mathrm{~h}$ exposure to different concentrations of $\mathrm{H}_{2} \mathrm{O}_{2}(100$ to $700 \mu \mathrm{M})$ (Fig. 1A). Interestingly, $L$. infantum $\left(\mathrm{EC}_{50}: 505+/-12.0 \mu \mathrm{M}\right)$ is more tolerant to exogenous $\mathrm{H}_{2} \mathrm{O}_{2}$ than $L$. braziliensis $\left(\mathrm{EC}_{50}: 395+/-11.5 \mu \mathrm{M}\right)$. In order to better compare the action of $\mathrm{H}_{2} \mathrm{O}_{2}$ in the parasite growth, we treated both Leishmania species with the same concentrations of $\mathrm{H}_{2} \mathrm{O}_{2}$ $(200,350$ and $400 \mu \mathrm{M})$ and verified the parasite growth during 4 to $168 \mathrm{~h}$ (Fig. 1B-C). Higher concentrations of $\mathrm{H}_{2} \mathrm{O}_{2}(350 \mu \mathrm{M}$ and $400 \mu \mathrm{M})$ are very toxic to $L$. braziliensis and significantly interfere in the parasite growth (Fig. 1B). In contrast, $L$. infantum survive/proliferate to different $\mathrm{H}_{2} \mathrm{O}_{2}$ concentrations and parasites treated with 200 , 350 and $400 \mu \mathrm{M} \mathrm{H}_{2} \mathrm{O}_{2}$ return the growth after 48, 72 and $96 \mathrm{~h}$, respectively after treatment (Fig. 1C).

The parasites growth curves determined during 4 to $168 \mathrm{~h}$ after exposure to $\mathrm{H}_{2} \mathrm{O}_{2}$ (Fig. 1B-C), show that at $350 \mu \mathrm{M} \mathrm{H}_{2} \mathrm{O}_{2}$, L. infantum is able to grow again after 48 $\mathrm{h}$ exposure to $\mathrm{H}_{2} \mathrm{O}_{2}$ and L. braziliensis remains stopped after $48 \mathrm{~h}$, revealing differences between the two species of Leishmania. Then the concentration of $350 \mu \mathrm{M} \mathrm{H}_{2} \mathrm{O}_{2}$ was chosen to analyse cell cycle progression, DNA damage and replication stress generation.

Comparative cell cycle analysis of L. braziliensis and $L$. infantum - We investigated cell cycle progression of wild-type $L$. braziliensis and $L$. infantum species parasites after 20 min treatment with $350 \mu \mathrm{M} \mathrm{H}_{2} \mathrm{O}_{2}$ and incubation in M199 medium during 24 and $72 \mathrm{~h}$. After this period, DNA content of propidium iodide-stained cells was analysed in a FACScan flow cytometer. Comparative analysis between $L$. braziliensis and L. infantum
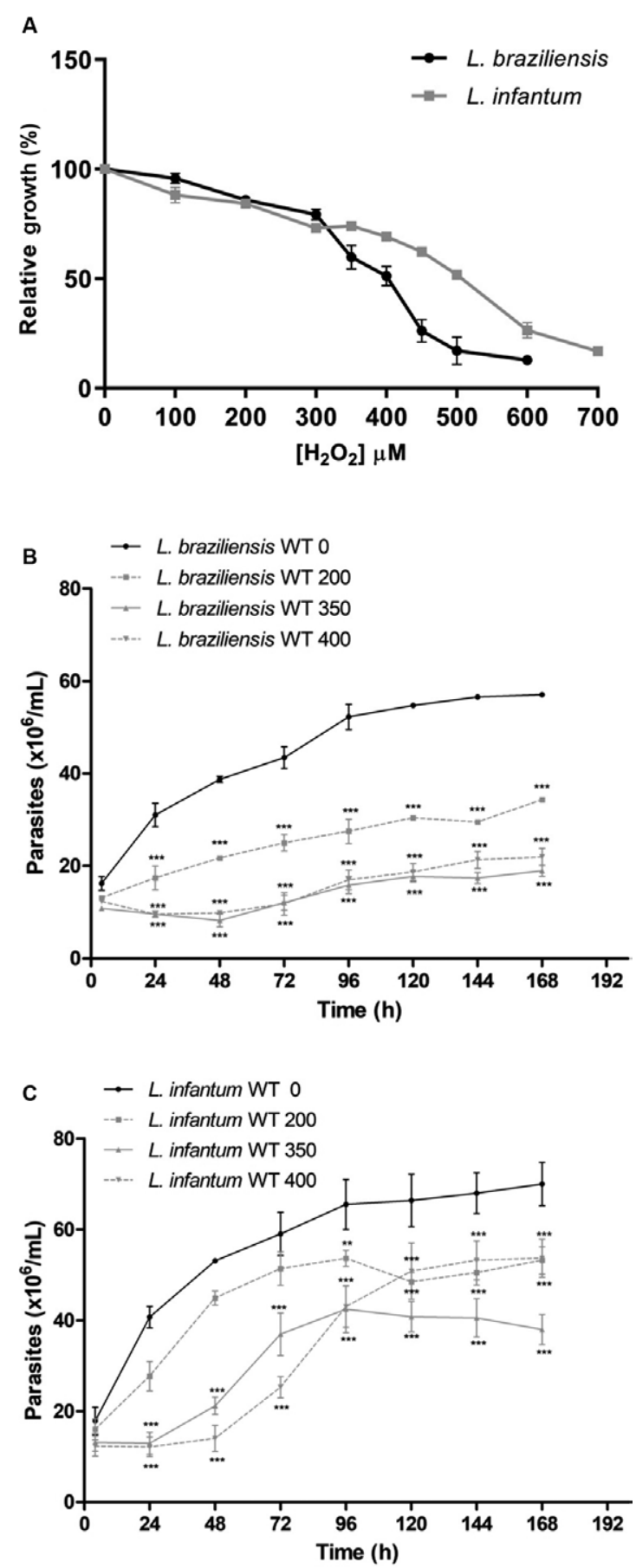

Fig. 1: Leishmania infantum are more tolerant to oxidative stress generated by $\mathrm{H}_{2} \mathrm{O}_{2}$ than $L$. braziliensis. (A) L. braziliensis and L. infantum parasites were incubated in the absence or presence of $\mathrm{H}_{2} \mathrm{O}_{2}(0$ to 700 $\mu \mathrm{M}$ ) in phosphate-buffered saline (PBS) for $20 \mathrm{~min}$, washed in PBS and incubated in M199 medium. The parasite number was determined using a model $\mathrm{Z} 1$ Coulter Counter after $48 \mathrm{~h}$ exposure to $\mathrm{H}_{2} \mathrm{O}_{2}$. (B) $L$. braziliensis and (C) L. infantum parasites were incubated in the absence or presence of $\mathrm{H}_{2} \mathrm{O}_{2}(0,200,350$ and $400 \mu \mathrm{M})$ for $20 \mathrm{~min}$, washed in PBS and incubated in M199 medium. The parasite number was determined during 4, 24, 48, 72, 96, 120, 144 and $168 \mathrm{~h}$ after exposure to $\mathrm{H}_{2} \mathrm{O}_{2}$. Mean values \pm standard deviations of three independent experiments in triplicate are indicated. The asterisk symbol (*) indicates the significant difference between non-treated parasites and parasites treated with different $\mathrm{H}_{2} \mathrm{O}_{2}$ concentrations and in each time point. Statistical analysis was performed based on analysis of variance (ANOVA) followed by Bonferroni test $(* * * p<0.001, * * \mathrm{p}<0.01, * \mathrm{p}<0.05)$. 
A

A
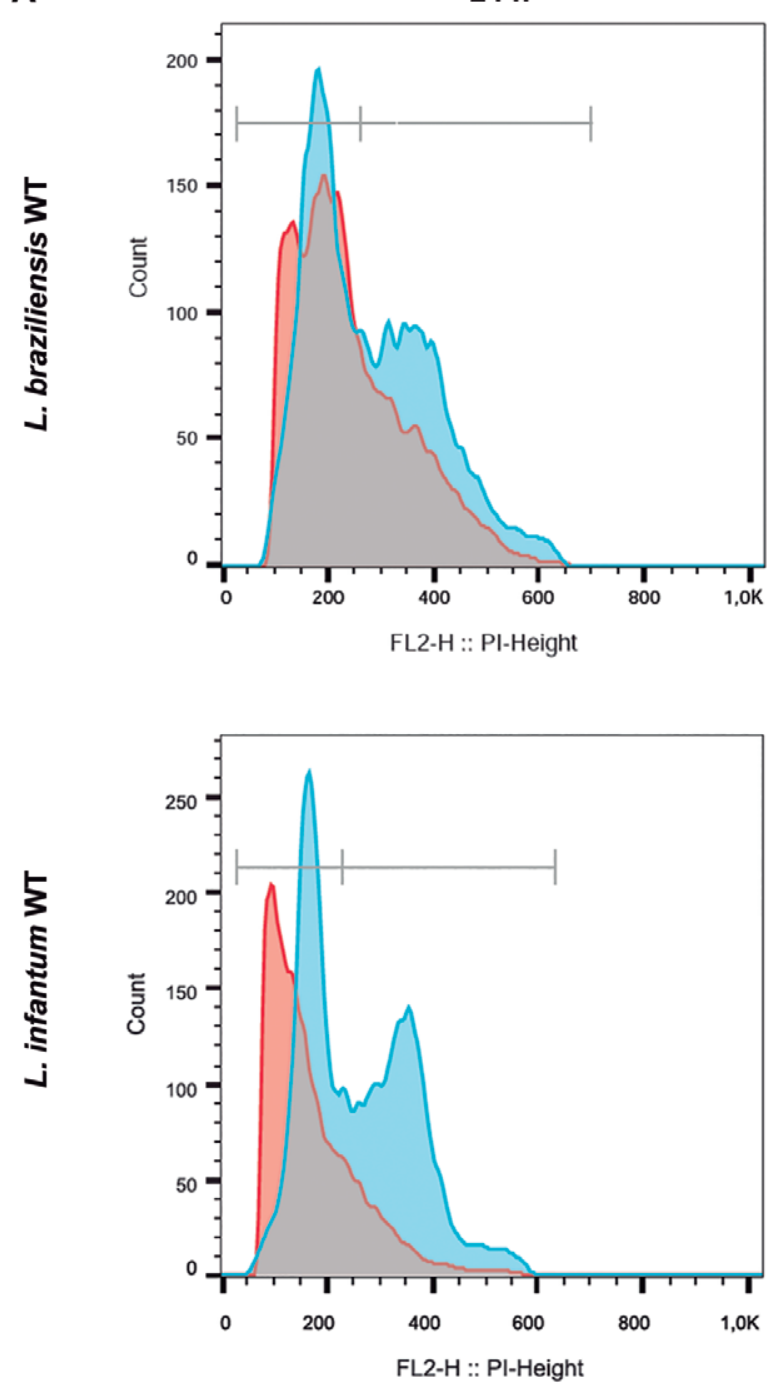

B

$24 \mathrm{~h}$

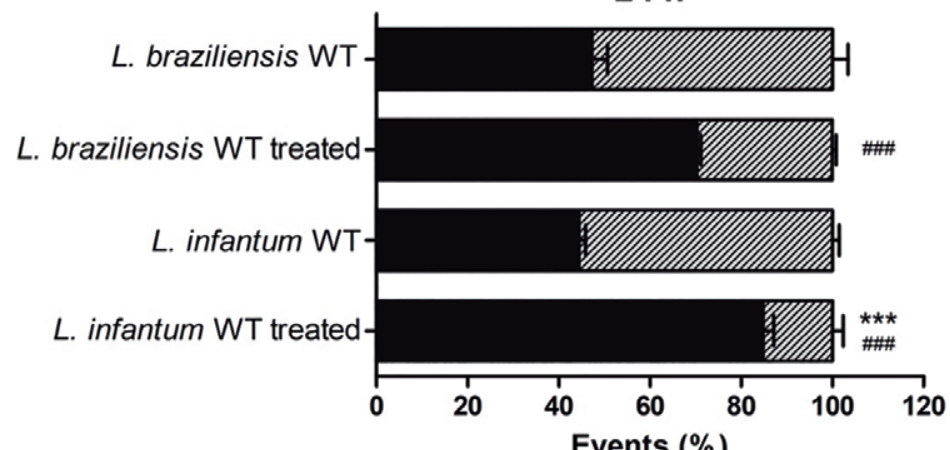

G1
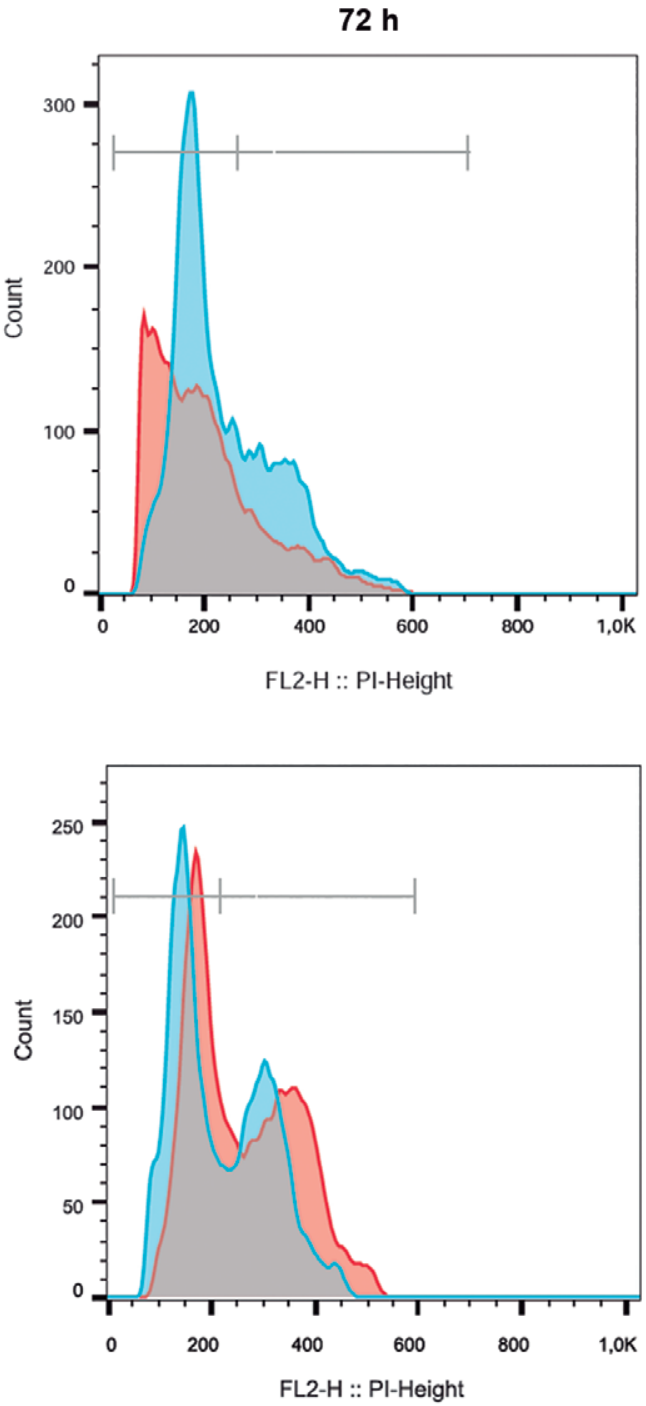

$72 \mathrm{~h}$

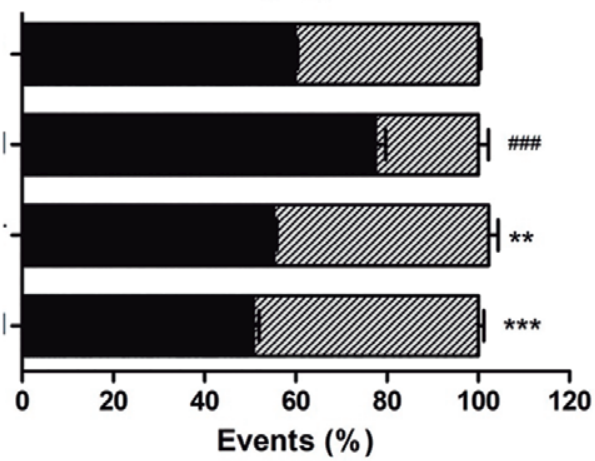

Fig. 2: cell cycle comparative analysis by flow cytometry of the Leishmania braziliensis and L. infantum after exposure to $\mathrm{H}_{2} \mathrm{O}_{2}$. The parasites were treated with $350 \mathrm{\mu M} \mathrm{H}_{2} \mathrm{O}_{2}$ in phosphate-buffered saline (PBS) for $20 \mathrm{~min}$, washed in PBS and incubated in M199 medium by 24 and $72 \mathrm{~h}$ The data represent at least three independent experiments performed in triplicate. (A) Representative histograms showing the DNA content of $L$. braziliensis and L. infantum. Peaks in light blue represent non-treated parasites and peaks in red treated with $\mathrm{H}_{2} \mathrm{O}_{2}$. (B) Quantitative analysis of parasites in each phase after $24 \mathrm{~h}$ or $72 \mathrm{~h}$ of incubation with or without $\mathrm{H}_{2} \mathrm{O}_{2}$. The asterisk symbol $(*)$ indicates the significant difference between L. braziliensis and L. infantum, treated with $\mathrm{H}_{2} \mathrm{O}_{2}$ or not. The hash symbol $\left({ }^{*}\right)$ indicates the significant difference between treated and non-treated parasites of the same sample. Statistical analysis was performed based on analysis of variance (ANOVA) followed by Bonferroni test $(* * * \mathrm{p}<$ $0.001,{ }^{* *} \mathrm{p}<0.01,{ }^{*} \mathrm{p}<0.05 ;$ or $\left.{ }^{\# \# \#} \mathrm{p}<0.001\right)$. 
species (Fig. 2), showed that in the presence of $\mathrm{H}_{2} \mathrm{O}_{2} L$. infantum presented a cell cycle arrest in G1 phase after $24 \mathrm{~h}$, and, after $72 \mathrm{~h}$ they restored the normal growth ratio. At $24 \mathrm{~h}$, only $18 \%$ of treated $L$. infantum parasites progress in the cell cycle, passing through $\mathrm{S}$ and G2 phases, whereas at $72 \mathrm{~h} 50 \%$ of these parasites are in the $\mathrm{S}$ and $\mathrm{G} 2$ phases showing similar profile compared to untreated parasites (Fig. 2B). L. infantum parasites can survive and restore growth after $72 \mathrm{~h}$ (Fig. 2B).

On the other hand, L. braziliensis has a different cell cycle profile, with little distinction between S and G2 phases. Treated parasites present less cells at S and G2 phases when compared with the non-treated parasites at $24 \mathrm{~h}$ and at $72 \mathrm{~h}$, however, L. braziliensis is not arrested in G1 phase as L. infantum was at $24 \mathrm{~h}$. On the other hand, $72 \mathrm{~h}$ after $\mathrm{H}_{2} \mathrm{O}_{2}$ treatment, only $22 \%$ of the L. braziliensis parasites continue to progress in the cell cycle, passing through $\mathrm{S}$ and $\mathrm{G} 2$ phases (Fig. 2B). Those results show that $L$. braziliensis was not able to restore growth $72 \mathrm{~h}$ after $\mathrm{H}_{2} \mathrm{O}_{2}$ treatment.

Leishmania spp. cell line expressing EcmutT gene - Multiple sequence alignment of the mutT amino acid sequences from E. coli and from Trypanosoma cruzi, $L$. braziliensis and L. infantum showed that elements for an enzyme from the nudix superfamily were identified in these Leishmania ssp. sequences [Supplementary data (Fig. 1)]. This is a family of enzymes that displays great catalytic versatility, ${ }^{(13)}$ which could indicate as candidate, but they are not necessarily a MutT pyrophosphohydrolase. Further studies need to be performed to confirm these data. The identity between the MutT amino acid sequences of L. braziliensis (LbrM.35.0380) and $L$. infantum (LinJ.36.0320) compared to T. cruzi TcMTH (AGM37761.1) was 43 and 46\%, respectively (data not shown). It is important to highlight that Aguiar et al. ${ }^{(20)}$ characterised the MutT gene in T. cruzi (TcMTH) and generated $T$. cruzi parasites heterologously expressing $E$. coli MutT or overexpressing the TcMTH enzyme. The authors observed the overexpression of the TcMTH gene in $T$. cruzi caused the same phenotypes observed when they expressed the $E$. coli MutT heterologous gene.
Wild-type L. braziliensis and L. infantum lines were transfected with the constructs containing the mutT gene from E. coli (pIR1BSD-EcmutT) to generate parasites expressing the EcMutT enzyme, and also with an empty vector (pIR1BSD) as a control. Linearisation of this vector allowed integration of the constructs into the ribosomal small subunit locus. ${ }^{(21)}$ To confirm the transfection, genomic DNA from the transfected clones was subjected to PCR assays using specific primers for the $B S D$ gene, which confers resistance to blasticidin. It was observed that all blasticidin-resistant clones (eight clones from each sample) showed a fragment of $399 \mathrm{bp}$, which corresponds to BSD marker (data not shown). The heterologous expression of $E$. coli mutT gene in the $L$. braziliensis and L. infantum cell lines was confirmed through RT-PCR (Fig. 3). The expected 115 bp fragment of the EcmutT gene was amplified from the cDNA of parasites transfected with pIR1BSD-EcmutT construct showing the presence of transcript of EcmutT gene in the clones of both Leishmania species analysed. A fragment of $69 \mathrm{bp}$ of the DNA polymerase I alpha constitutive gene, used as control of the assay, was amplified in all samples analysed, except those without reverse transcriptase (RT-PCR negative control).

As the EcMut protein expression was not evaluated, it can not exclude the possibility that the heterologous expression of $E$. coli MutT enzyme could be being differentially expressed in L. braziliensis and L. infantum.

The ectopic expression of E. coli MutT does not interfere in parasite growth or in susceptibility to trivalent antimony $\left(S b^{I I I}\right)$ - To verify whether the expression of $E$. coli mutT gene alter the growth of parasites, promastigotes from $L$. braziliensis and $L$. infantum transfected with the constructs pIR1BSD (empty vector), pIR1BSDEcMutT and untransfected parasites were incubated in M199 medium during 4 to $168 \mathrm{~h}$ [Supplementary data (Fig. 2)]. The growth curves of the EcmutT-expressing lines from $L$. braziliensis and L. infantum were very similar to their respective wild-type non-transfected parasites. The EcMutT heterologous expression did not alter L. braziliensis and L. infantum growth.
A

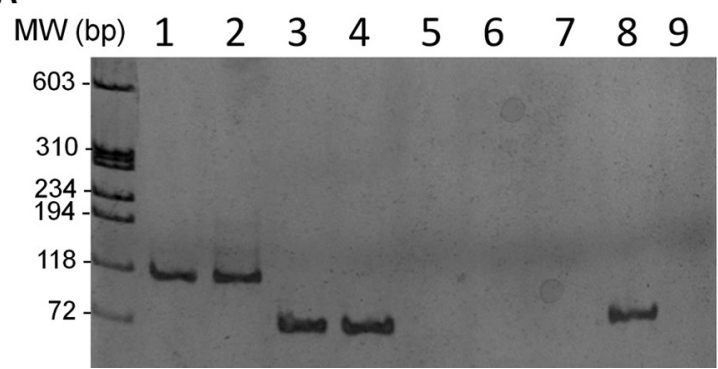

B

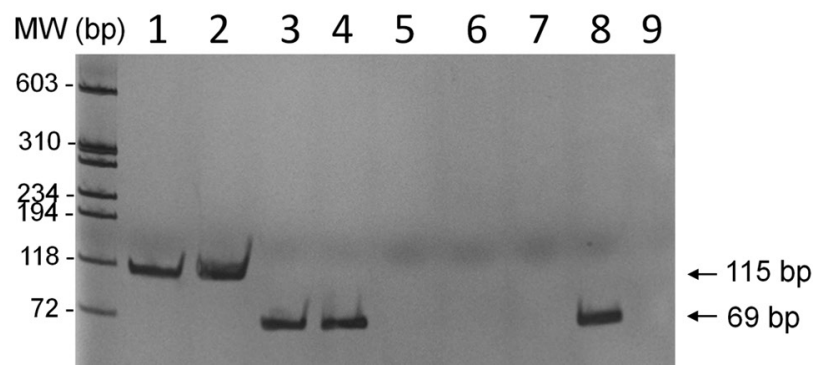

Fig. 3: reverse transcription polymerase chain reaction (RT-PCR) of Leishmania braziliensis (A) and L. infantum (B). RT-PCR was performed to confirm expression of the EcmutT gene in the cDNA of parasites transfected with pIR1BSD-EcmutT construct: clones 16 and 24 from $L$. braziliensis (lanes 1 and 2 - A) and clones 1 and 13 from L. infantum (lanes 1 and 2 - B). Electrophoresis was performed on a $6 \%$ polyacrylamide gel stained with silver nitrate. The expected 115 bp fragment of EcmutT gene was amplified in both clone lines of Leishmania transfected with pIR1BSD-EcMutT (lanes 1 and 2). DNA polymerase was used as quantitative control of RT-PCR reaction, showing fragment of 69 bp (lanes 3 and 4). As control of RT-PCR was used samples of mRNA without the reverse transcriptase enzyme (lanes 5 and 6 ), showing absence of amplification for both EcMutT and DNA polymerase genes. As control also was used genomic DNA of wild-type non-transfected parasites presenting only amplification of the DNA polymerase gene (lane 8) and not EcmutT gene (lane 7). Negative control of reaction without template (lane 9). The molecular weight markers were derived from $\Phi 174$ DNA digested with HaeIII (Promega). 
A

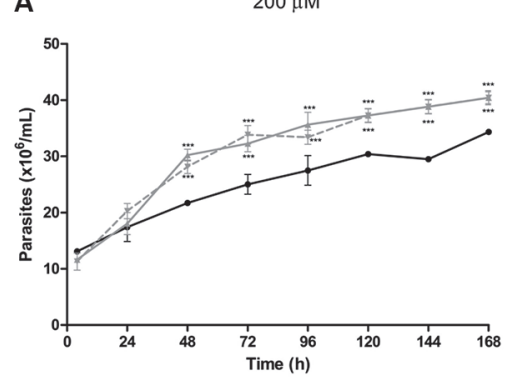

$350 \mu \mathrm{M}$

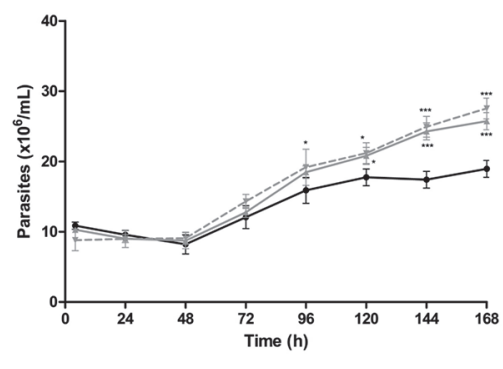

-r. L. braziliensis MutT cl24
B

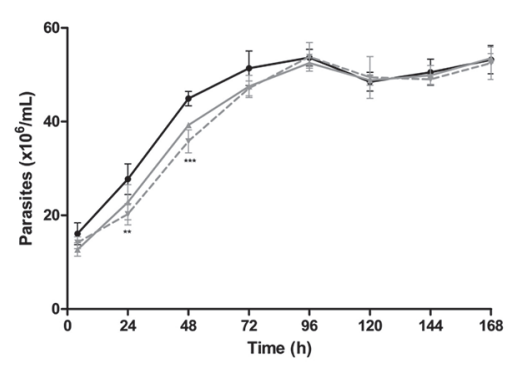

$350 \mu \mathrm{M}$

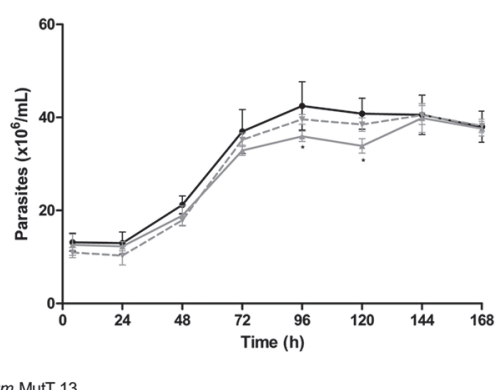

$400 \mu \mathrm{M}$

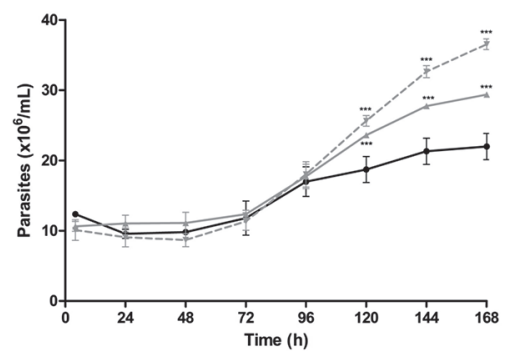

$400 \mu \mathrm{M}$

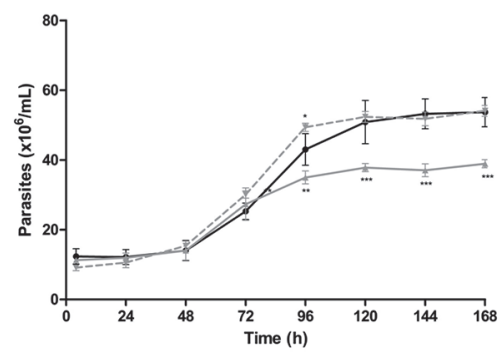

$\rightarrow$ L. infantum WT $\quad-$ L. infantum MutT c1 $\quad$-r. L infantum MutT 13

Fig. 4: EcMutT heterologous expression increases the resistance to $\mathrm{H}_{2} \mathrm{O}_{2}$ in Leishmania braziliensis (A) but not in L. infantum (B). Wild-type (WT) and transfected with pIR1-BSD-EcMutT (MutT) L. braziliensis (Lb) and L. infantum (Li) parasites were incubated with $\mathrm{H}_{2} \mathrm{O}_{2}(200,350$ and $400 \mu \mathrm{M}$ ) in phosphate-buffered saline (PBS) for $20 \mathrm{~min}$, washed in PBS and incubated in M199 medium. The parasite number was determined using a model $\mathrm{Z1}$ Coulter Counter during 4, 24, 48, 72, 96, 120, 144 and $168 \mathrm{~h}$ after exposure to $\mathrm{H}_{2} \mathrm{O}_{2}$. Mean values \pm standard deviations of three independent experiments in triplicate are indicated. The asterisk symbol $(*)$ indicates the significant difference between wild-type parasites and those transfected with EcMutT, treated with each $\mathrm{H}_{2} \mathrm{O}_{2}$ concentration and in each time of growth. Statistical analysis was performed based on analysis of variance (ANOVA) followed by Bonferroni test $(* * * \mathrm{p}<0.001, * * \mathrm{p}<0.01, * \mathrm{p}<0.05$ ).

We also investigated whether the expression of $E c$ $m u t T$ gene contributes to antimony resistance phenotype in Leishmania. For this, E. coli MutT-expressing L. braziliensis and L. infantum clonal lines and non-transfected parasites were incubated with different $\mathrm{Sb}^{\mathrm{III}}$ concentrations during $48 \mathrm{~h}$ [Supplementary data (Fig. 3)]. The $\mathrm{EC}_{50}$ was determined by counting the number of parasites that grew in the absence or presence of this drug. EcMutTexpressing L. braziliensis and L. infantum lines did not show an increase in resistance towards $\mathrm{Sb}^{\mathrm{III}}$, since that the $\mathrm{Sb}^{\mathrm{III}} \mathrm{EC}_{50}$ of these lines were very similar to respective wild-type non-transfected parasites. The results revealed that the $\mathrm{Sb}^{\mathrm{III}} \mathrm{EC}_{50}$ of wild-type L. braziliensis line was $2.66( \pm 0.22) \mu \mathrm{M}$, and the EcmutT expressing clones 16 and 24 were $3.04( \pm 0.26) \mu \mathrm{M}$ and $2.98( \pm 0.21) \mu \mathrm{M}$, respectively [Supplementary data (Fig. 3A)]. Regarding $L$. infantum, we observed that $\mathrm{Sb}^{\mathrm{III}} \mathrm{EC}_{50}$ of wild-type line was $53( \pm 0.61) \mu \mathrm{M}$ and EcmutT-expressing clones 1 and 13 were $53( \pm 2.34) \mu \mathrm{M}$ and $55( \pm 2.7) \mu \mathrm{M}$, respectively [Supplementary data (Fig. 3B)]. It is important to mention that the pIR1-BSD vector did not interfere in the $\mathrm{Sb}^{\mathrm{III}}$ susceptibility since no difference in $\mathrm{Sb}^{\mathrm{III}} \mathrm{EC}_{50}$ was observed between parasites non-transfected and transfected with empty vector (data not shown).

Tolerance of EcMutT expressing Leishmania spp. lines to hydrogen peroxide $\left(\mathrm{H}_{2} \mathrm{O}_{2}\right)$ - We also investigated whether the expression of EcmutT gene alter Leishmania response to oxidative stress generated by $\mathrm{H}_{2} \mathrm{O}_{2}$. Comparative analysis showed that both EcMutT expressing clones 16 and 24 from L. braziliensis were more resistant to oxidative stress generated by $\mathrm{H}_{2} \mathrm{O}_{2}$ compared to untransfected wild-type parasites (Fig. $4 \AA$ ) or parasites transfected with empty vector (data not shown). At 200 $\mu \mathrm{M} \mathrm{H} \mathrm{H}_{2}$, L. braziliensis expressing EcMutT restore their growth after $48 \mathrm{~h}$ of incubation. Higher concentrations of $\mathrm{H}_{2} \mathrm{O}_{2}(350 \mu \mathrm{M}$ and $400 \mu \mathrm{M})$ are toxic to $L$. braziliensis, but the EcmutT-expressing parasites present better growth than wild-type line (Fig. 4A).

We also determined the $\mathrm{H}_{2} \mathrm{O}_{2}, \mathrm{EC}_{50}$ for different clones incubated in the presence of several concentrations of $\mathrm{H}_{2} \mathrm{O}_{2}$ for $48 \mathrm{~h}$ and the results revealed that the $\mathrm{H}_{2} \mathrm{O}_{2} \mathrm{EC}_{50}$ of wild-type L. braziliensis line was $395 \mu \mathrm{M}$, and the EcMutT expressing L. braziliensis lines clones 16 and 24 were 456 and $443 \mu \mathrm{M}$, respectively. These data suggest that MutT is involved in the protection against oxidative stress generated by $\mathrm{H}_{2} \mathrm{O}_{2}$ in $L$. braziliensis.

On the other hand, EcmutT-expressing L. infantum lines did not alter the $\mathrm{H}_{2} \mathrm{O}_{2}$ susceptibility, since that the parasites present similar growth curve compared to untransfected wild-type parasites (Fig. 4B). However, $L$. infantum clone 1 has its resistance decreased at $400 \mu \mathrm{M}$ $\mathrm{H}_{2} \mathrm{O}_{2}$ during period of 72 to $168 \mathrm{~h}$ after exposure to $\mathrm{H}_{2} \mathrm{O}_{2}$. The same was not observed for $L$. infantum clone 13 that presented similar growth curve compared to wild-type parasites in all $\mathrm{H}_{2} \mathrm{O}_{2}$ concentrations evaluated. 
Testing different $\mathrm{H}_{2} \mathrm{O}_{2}$ concentrations for $48 \mathrm{~h}$ we observed that the $\mathrm{H}_{2} \mathrm{O}_{2} \mathrm{EC}_{50}$ of wild-type $L$. infantum line was $505 \mu \mathrm{M}$, and the EcMutT-expressing L. infantum lines clones 1 and 13 were 499 and $490 \mu \mathrm{M}$, respectively. Thus, the results indicated that MutT is not important in the protection against the oxidative stress generated by $\mathrm{H}_{2} \mathrm{O}_{2}$ in L. infantum.

Cell cycle analysis of EcmutT expressing L. braziliensis - Comparative analysis of cell cycle between wildtype and EcmutT-expressing L. braziliensis after $\mathrm{H}_{2} \mathrm{O}_{2}$ treatment showed that at $24 \mathrm{~h}$ the cell cycle profile was similar between these parasites (Fig. 5). On the other hand, at $72 \mathrm{~h}$ after $\mathrm{H}_{2} \mathrm{O}_{2}$ treatment, while $22.6 \%$ of wildtype L. braziliensis are in the $\mathrm{S}$ and $\mathrm{G} 2$ phases, $38.6 \%$ of the EcmutT-expressor clone 16, continue to progress in the cell cycle, passing through S and G2 phases (Fig. $5 \mathrm{~B}$ ), restoring the normal growth ratio. At $72 \mathrm{~h}$ after $\mathrm{H}_{2} \mathrm{O}_{2}$ exposure, different of wild-type $L$. braziliensis, the cell cycle profile of EcMutT-expressor clone 16 is very similar to untreated parasites. These results show that the expression of the EcmutT gene protects $L$. braziliensis parasites against $\mathrm{H}_{2} \mathrm{O}_{2}$ effect. No difference in the cell cycle profile was observed between parasites non-transfected and transfected with empty vector (data not shown).

Leishmania spp. expressing EcmutT decreased replication stress caused by $\mathrm{H}_{2} \mathrm{O}_{2}$ - Leishmania spp. has shown sensibility to $\mathrm{H}_{2} \mathrm{O}_{2}$ treatment which results in cell cycle arrest. To investigate this phenotype, we tested the capacity of wild-type (WT) and EcmutT-expressing cell lines to generate the replication stress after $\mathrm{H}_{2} \mathrm{O}_{2}$ treatment. The heterochromatin modification of histone $\mathrm{H} 2 \mathrm{~A}$ to $\gamma \mathrm{H} 2 \mathrm{~A}$ is a biomarker of genotoxic stress. ${ }^{(22)}$ After 30 min of exposition, no difference of $\gamma \mathrm{H} 2 \mathrm{~A}$ activation was observed between WT and EcMutT parasites of both Leishmania species analysed (Lb) and (Li) (Fig. 6A1). Interestingly, $4 \mathrm{~h}$ after $\mathrm{H}_{2} \mathrm{O}_{2}$ treatment, L. braziliensis EcMutT-expressing clone 24 demonstrated lower activation of $\gamma \mathrm{H} 2 \mathrm{~A}$ than its parental non-transfected parasites (Fig. 6A2). Analysis of replication stress was performed using the BrdU native detection assay. The presence of BrdU in single strand DNA strongly suggests replication stress. ${ }^{(23)}$ After $1 \mathrm{~h} \mathrm{H} \mathrm{H}_{2}$ treatment $L$. infantum parasites presented lower replication stress than L. braziliensis (Fig. 6B-C). These results are in accordance with the fact that $L$. infantum is more arrested in G1 phase after $\mathrm{H}_{2} \mathrm{O}_{2}$ treatment. The importance of incorporation of 8-oxoG to generate replication stress is evidenced by the fact that EcMutT-expressing clones decreased $68.35 \%( \pm 0.5)$ of replication stress foci in L. braziliensis and $30.25 \%$ ( \pm 0.15 ) in L. infantum (Fig. 6B-C).

\section{DISCUSSION}

Leishmania needs an effective antioxidant defense system since that the parasite is constantly exposed to reactive oxygen species, produced by anti-leishmania drugs or intrinsic host processes. After infection into vertebrate host, Leishmania spp. are phagocytised by macrophages, triggering various reactions of the host defense system. A series of factors act during the activating oxidative process, the main one being the lesions in the DNA, which can be caused, most of the times, by the incorporation of 8-oxoG since it is one of the most abundant oxidative lesions. ${ }^{(10)}$ Therefore, the presence of an enzyme responsible for repairing or even preventing such lesions is essential, as is the case of the MutT enzyme, which can hydrolyze 8-oxo-dGTP to 8-oxo-dGMP present in the pool of nucleotides, preventing the incorporation of oxidised guanine during the DNA replication. ${ }^{(24)}$ Foti et al. ${ }^{(25)}$ demonstrated that the oxidation of guanine to 8-oxoG in the nucleotide pool is one of the forms that antibiotics use to generate cell death, so it is very important to have an enzyme sanitising the cell environment.

In this work we compared the tolerance to oxidative stress and the cell cycle of two different Leishmania species, L. infantum and L. braziliensis, that causes different clinical forms of disease: visceral leishmaniasis or cutaneous leishmaniasis, respectively. We observed that L. braziliensis species is more susceptible to hydrogen peroxide when compared to L. infantum. Interestingly, L. braziliensis also are more susceptible to $\mathrm{Sb}^{\mathrm{III}}$ than L. infantum. ${ }^{(16)}$ Surface glycoconjugate polymorphisms between $L$. infantum and L. braziliensis may possibly cause differences in susceptibility to oxidative stress generated by $\mathrm{H}_{2} \mathrm{O}_{2}$. Lipophosphoglycan (LPG) from the procyclic promastigote form of L. braziliensis (M2903) is devoid of side chains, whereas L. infantum (PP75) possesses $\beta$-glucose residues in approximately one-third of the repeat unit. ${ }^{(26)}$ This interspecies LPG variation is able to differentially modulate the host cell response. ${ }^{(27)}$

In order to better understand this difference in oxidative stress susceptibility, we evaluated the cell cycle of these parasites. Cell cycle analysis showed that $L$. infantum, after treatment with $\mathrm{H}_{2} \mathrm{O}_{2}$, remains for a longer time in the G1 phase. By not allowing to progress past the G1 checkpoint, $L$. infantum avoid lesions in DNA caused by 8 -oxoG incorporation and generate less replication stress. Thus, the $L$. infantum parasites can survive and restore growth after $72 \mathrm{~h}$. In the other hand, L. braziliensis continue to progress in the cell cycle even in the presence of oxidative stress. Despite of this progression through cell cycle, we observe that, L. braziliensis is more sensitive to oxidative stress generated by $\mathrm{H}_{2} \mathrm{O}_{2}$. We believe that this occurs because, by allowing progression of the cell cycle, even under unfavorable conditions, the incorporation of 8-oxoG generate replication stress that could generate DNA double-strand break.

To evaluate if EcMutT enzyme is involved in response to oxidative stress, we generated L. braziliensis and L. infantum parasites heterologously expressing $E$. coli MutT. Interestingly, L. braziliensis expressing EcMutT exhibited higher resistance to $\mathrm{H}_{2} \mathrm{O}_{2}$ and presented lower activation of $\gamma \mathrm{H} 2 \mathrm{~A}$, a biomarker of genotoxic stress, than nontransfected wild-type parasites. These results show that EcMutT in L. braziliensis is involved in the protection against the oxidative stress generated by $\mathrm{H}_{2} \mathrm{O}_{2}$. Analysis of replication stress using the BrdU native detection assay revealed that L. braziliensis EcMutT-expressing clone decreased $68.35 \%$ of replication stress. As this cell continue to progress to $\mathrm{S}$ phase even in the presence of $\mathrm{H}_{2} \mathrm{O}_{2}$, we showed that an excess of MutT enzyme could reduce the quantity of 8-oxoG and, as consequence, re- 
A
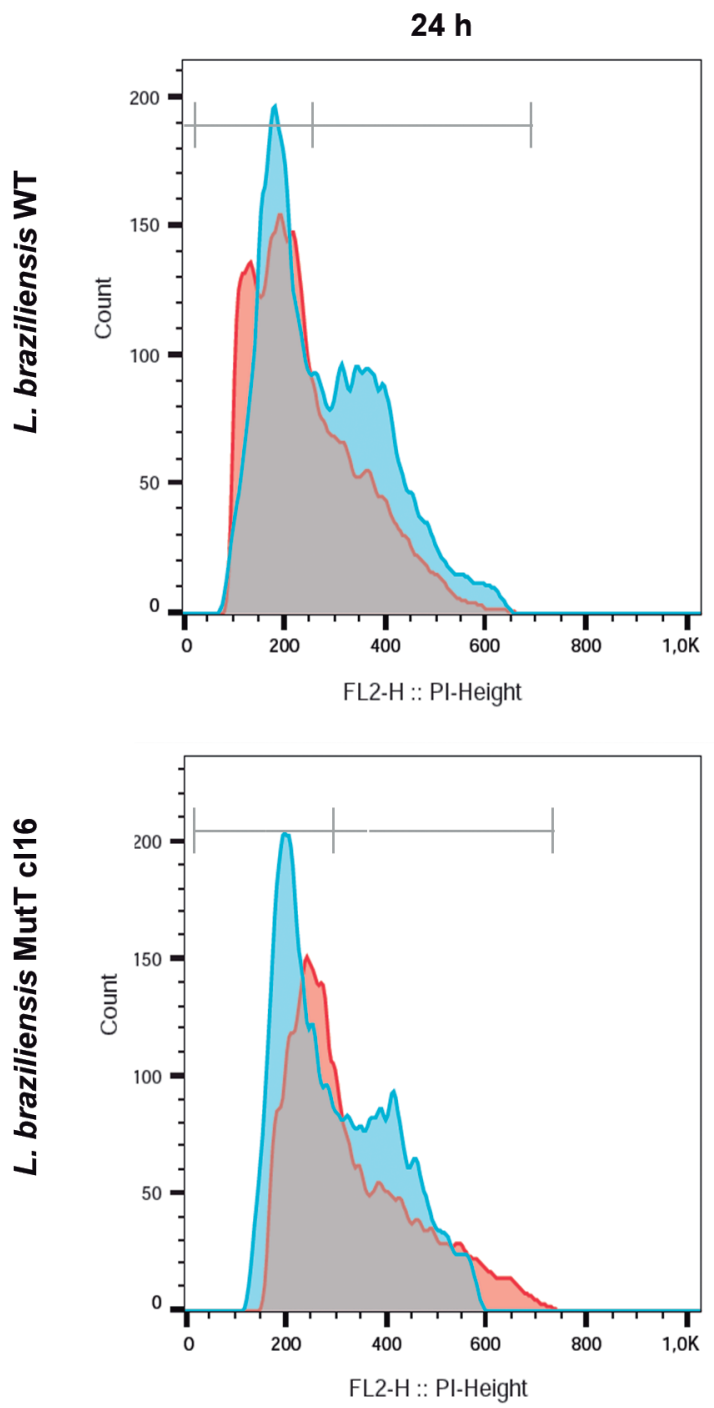

B

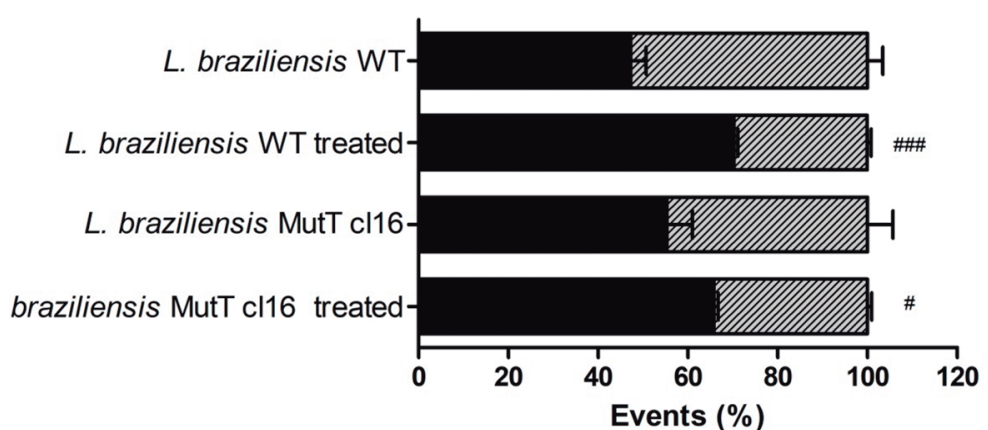

G1
$24 \mathrm{~h}$

SG2
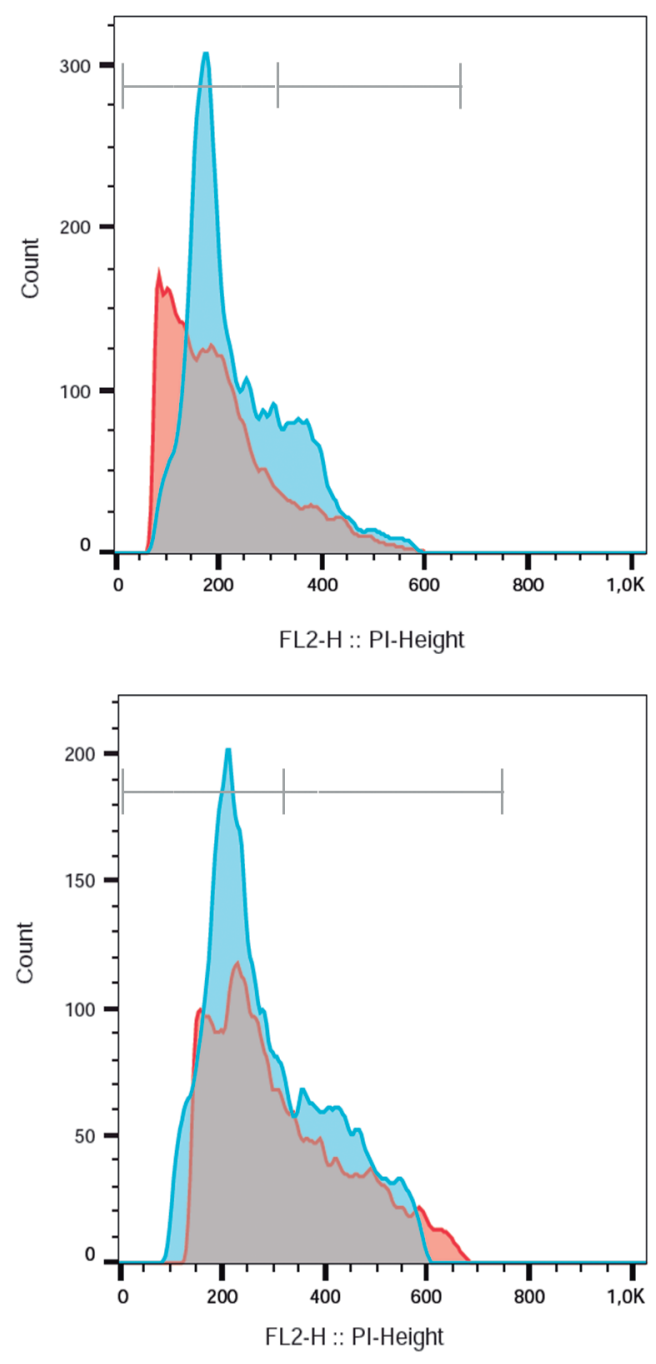

$72 \mathrm{~h}$

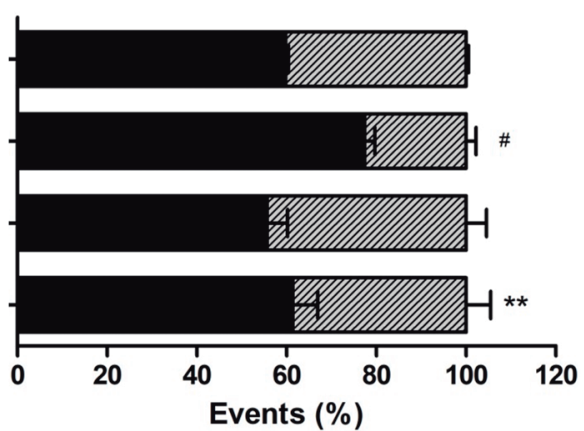

Fig. 5: cell cycle comparative analysis by flow cytometry of the wild-type (WT) and clonal lines transfected with pIR1-BSD-EcMutT (EcMutT clone 16) Leishmania braziliensis (Lb) parasites after exposure to $\mathrm{H}_{2} \mathrm{O}_{2}$. The parasites were treated with $350 \mu \mathrm{M} \mathrm{H}_{2} \mathrm{O}_{2}$ in phosphate-buffered saline (PBS) for $20 \mathrm{~min}$, washed in PBS and incubated in M199 medium by 24 and $72 \mathrm{~h}$. The data represent at least three independent experiments performed in triplicate. (A) Representative histograms showing the DNA content of L. braziliensis WT and clonal lines. Peaks in light blue represent non-treated parasites and peaks in red treated with $\mathrm{H}_{2} \mathrm{O}_{2}$. (B) Quantitative analysis of parasites in each phase after $24 \mathrm{~h}$ or $72 \mathrm{~h}$ of incubation with or without $\mathrm{H}_{2} \mathrm{O}_{2}$. The asterisk symbol $\left(^{*}\right)$ indicates the significant difference between L. braziliensis WT and clonal lines, treated with $\mathrm{H}_{2} \mathrm{O}_{2}$ or not. The hash symbol $(*)$ indicates the significant difference between treated and non-treated parasites of the same sample. Statistical analysis was performed based on analysis of variance (ANOVA) followed by Bonferroni test $\left(* * \mathrm{p}<0.01 ; * \mathrm{p}<0.05\right.$; ${ }^{\# \# \#} \mathrm{p}<0.001$, \#\# $\mathrm{p}<0.01$, ${ }^{*} \mathrm{p}<0.05$ ). 


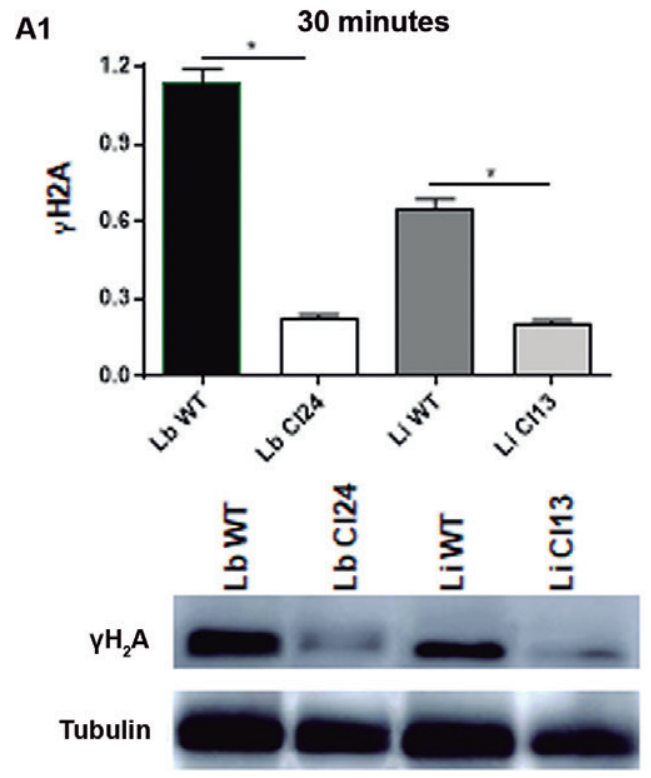

B

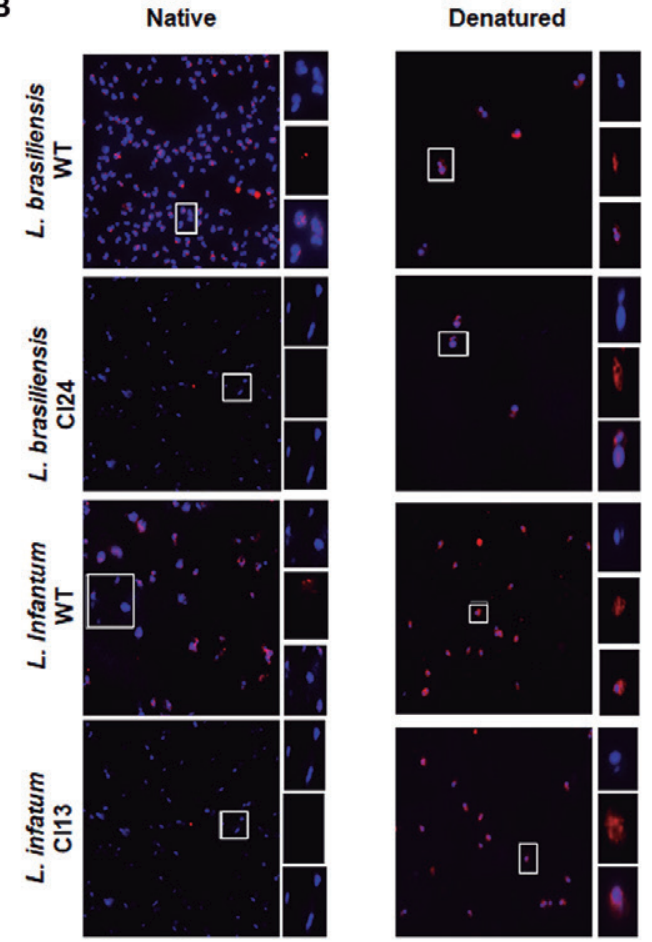

A2
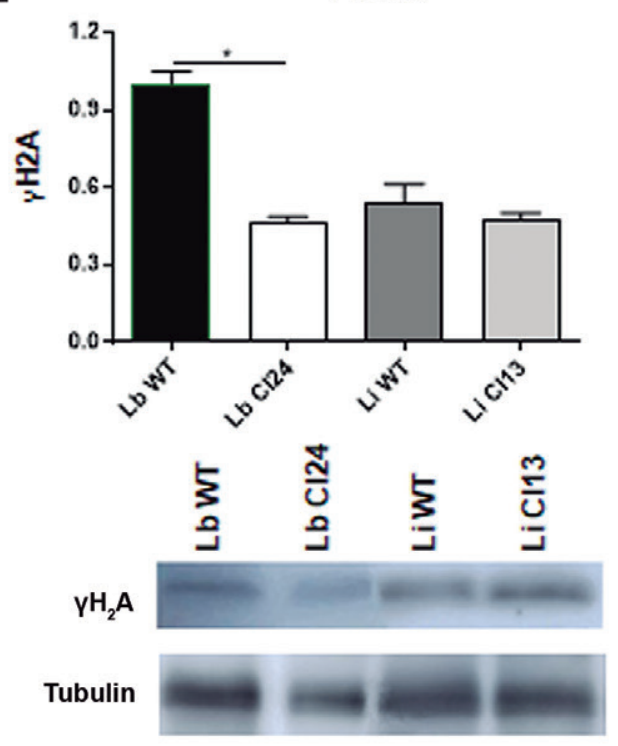

C

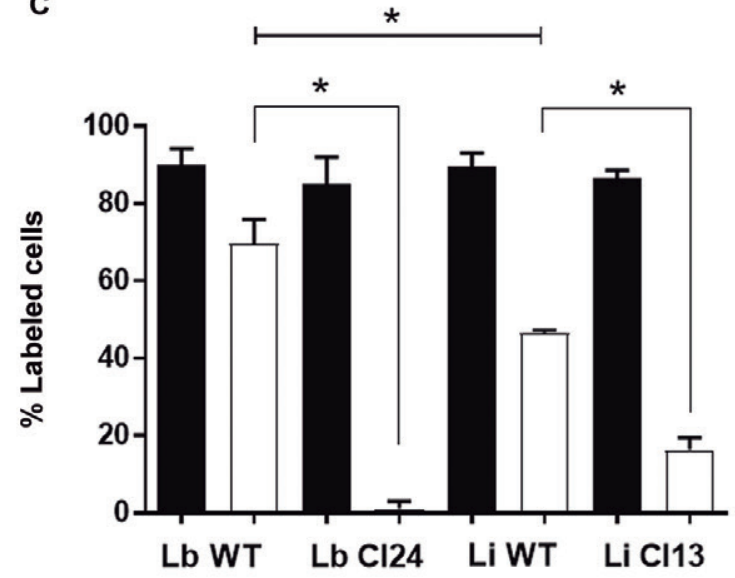

Denatured

Native

Fig. 6: EcMutT expression reduces replication stress in Leishmania braziliensis and L. infantum. (A) Cells were treated with $350 \mu \mathrm{M} \mathrm{H}_{2} \mathrm{O}_{2}$ in phosphate-buffered saline (PBS) for $20 \mathrm{~min}$, washed in PBS and incubated with M199 during $30 \mathrm{~min}$ and $4 \mathrm{~h}$ and then submitted to protein extraction and immunoblotting assays for $\gamma \mathrm{H} 2 \mathrm{~A}$. Proteins were separated by electrophoresis on $15 \%$ sodium dodecyl sulfate (SDS)-polyacrylamide gel and transferred onto nitrocellulose membranes. The blots were probed with rabbit anti- $\gamma \mathrm{H} 2 \mathrm{~A}(1: 3,000)(\mathrm{A} 1, \mathrm{~A} 2)$ antibody and developed using ECL Plus kit. The membranes were incubated with the anti- $\alpha$-tubulin monoclonal $(1: 5,000)$ antibody for normalisation of the results. Quantification of the bands was done by densitometric analysis using the software GelAnalyzer 2010 (gelanalyzer.com) and the ratios found for each sample analysed are shown in the Fig. (A1, A2). (B) The cells were treated with $350 \mu \mathrm{M} \mathrm{H}_{2} \mathrm{O}_{2}$ and $100 \mu \mathrm{M}$ of 5-bromo-2'-deoxyuridine (BrdU) for $1 \mathrm{~h}$ to allow its incorporation into DNA. Parasite were washed, fixed and then deposited onto slides pre-treated with $0.1 \%$ poly-L-lysine. To ensure all cells incorporated BrdU, aliquots of each sample analysed were subjected to DNA denaturation using $2.5 \mathrm{M} \mathrm{HCl}$ for 20 min. Then, the samples were divided into two groups; native and denatured. BrdU was detected using rat anti- $\alpha$-BrdU (1:250) antibody followed by incubation with secondary antibody Alexa Fluor 555-conjugated anti-rat (1:1,000). ProLong ${ }^{\circledR}$ Diamond Antifade Mountant with DAPI was used to be anti-fade mounting solution and to stain organelles containing DNA (i.e., nucleus and kinetoplast). Images were captured using Axio Imager fluorescence microscope coupled with a digital camera, and analyzed using Zen software (C) Replication stress foci appearance was higher in WT $L$. braziliensis than $L$. infantum, and Ecmut T expressing clones of both species decreased significantly the replication stress. The measurement of the parasites showing presence of ssDNA foci (\% labeled cells) was made using ImageJ software. Statistical analysis was performed using Student's $t$ test $(* \mathrm{p}<0.001)$. 
duce the level of replication stress in $\mathrm{S}$ phase. These data corroborate with previous results showing that $T$. cruzi expressing E. coli MutT gene are more resistant to $\mathrm{H}_{2} \mathrm{O}_{2}$ treatment than wild-type parasites. ${ }^{(20)}$

In contrast to L. braziliensis, expression of E. coli $m u t T$ gene in L. infantum did not alter the susceptibility of parasites to $\mathrm{H}_{2} \mathrm{O}_{2}$. Probably it is due to the fact that L. infantum are already more resistant to $\mathrm{H}_{2} \mathrm{O}_{2}$, and, in this way, the excess of MutT is not directly involved in the protection against the oxidative stress generated by $\mathrm{H}_{2} \mathrm{O}_{2}$ in this species. The cell cycle profile of this species confirms these data, since after exposure to $\mathrm{H}_{2} \mathrm{O}_{2}$ this species arrests the growth in G1 phase and the 8 oxoG generated could be degraded in this phase before the $\mathrm{S}$ phase, so the normal quantity of MutT enzyme in L. infantum is sufficient. As the 8 -oxoG is less incorporated, L. infantum recover the growth faster than L. braziliensis, being more resistant to the action of oxidants and can escape faster from the effects of these agents.

In relation to $\mathrm{Sb}^{\mathrm{III}}$ susceptibility test, the results demonstrated that the expression of EcMutT did not affect the antimony resistance phenotype in both L. braziliensis and $L$. infantum species. These data suggest that excess of MutT in Leishmania is not directly involved in the protection of parasites from the effect of $\mathrm{Sb}^{\mathrm{III}}$. In $T$. cruzi, MutT exerts an important defense function against the effects caused by benznidazole, ${ }^{(28)}$ what was demonstrated when $T$. cruzi overexpressing the E. coli $m u t T$ gene had a benznidazole resistance index 3-fold higher than the parental parasites.

In other studies, carried out by our group, it was demonstrated that the overexpression of enzymes from antioxidant defense pathway, triparedoxin peroxidase ${ }^{(29)}$ and iron superoxide dismutase ${ }^{(30)}$ increased the resistance of Leishmania spp. to trivalent antimony. These data demonstrate the involvement of these antioxidant defense enzymes in the resistance phenotype of Leishmania spp. to antimony. Probably, the E. coli MutT 8-oxo-dGTPase activity is not directly involved in the $\mathrm{Sb}^{\mathrm{III}}$ resistance phenotype.

Comparative analysis of cell cycle showed that at 72 $\mathrm{h}$ after $\mathrm{H}_{2} \mathrm{O}_{2}$ exposure, the wild-type $L$. braziliensis parasites presented an increase in G1 phase and retention in the S/G2 phases. In contrast, EcMutT-expressor L. braziliensis clone 16 recovered their proliferation capacity, restoring the normal growth ratio. These results suggest that the expression of exogenous MutT allows an improved control of oxidised nucleotide incorporation to DNA, preventing lesions that can arise from it, emphasising the importance of 8-oxo-dGTPase hydrolysis. These results agree with previous data showing the importance of oxidised nucleotide clearance in bacteria ${ }^{(25)}$ and T. cruzi. ${ }^{(20)}$

The results obtained in this work reveal that $L$. infantum species is more resistant to stress generated by $\mathrm{H}_{2} \mathrm{O}_{2}$ than $L$. braziliensis and that $L$. braziliensis and $L$. infantum present important differences in the cell cycle. We hypothesised that there is probably a lower incorporation of 8-oxoG by L. infantum, which results in lower number of double-strand breaks in DNA compared to $L$. braziliensis. The excess of MutT enzyme is involved in the protection against oxidative stress in L. braziliensis, but not in L. infantum.

\section{ACKNOWLEDGEMENTS}

To the Program for Technological Development in Tools for Health-PDTIS-FIOCRUZ for use of its facilities.

\section{AUTHORS' CONTRIBUTION}

LCA, AMMS, CLA, WRRF, AVA, EO, CRM and SMFM - Designed and performed the experiments, analysed the data, wrote and reviewed the full manuscript.

\section{REFERENCES}

1. WHO - World Health Organization. Leishmaniasis. Available from: http://www.who.int/leishmaniasis/disease/en/. Accessed 14 December 2019.

2. Alvar J, Velez ID, Bern C, Herrero M, Desjeux P, Cano J, et al. Leishmaniasis worldwide and global estimates of its incidence. PLoS One. 2012; 7(5): e35671.

3. Burza S, Croft SL, Boelaert M. Leishmaniasis. Lancet. 2018; 392(10151): 951-70.

4. Frézard F, Demicheli C, Ferreira CS, Costa MA. Glutathione-induced conversion of pentavalent antimony to trivalent antimony in meglumine antimoniate. Antimicrob Agents Chemother. 2001; 45(3): 913-6.

5. Berman JD, Gallalee JV, Best JM. Sodium stibogluconate (Pentostam) inhibition of glucose catabolism via the glycolytic pathway, and fatty acid $\beta$-oxidation in Leishmania mexicana amastigotes. Biochem Pharmacol. 1987; 36(2): 197-201.

6. Wyllie S, Cunningham ML, Fairlamb AH. Dual action of antimonial drugs on thiol redox metabolism in the human pathogen Leishmania donovani. J Biol Chem. 2004; 279: 39925-32.

7. David SS, O'shea VL, Kundu S. Base-excision repair of oxidative DNA damage. Nature. 2007; 447(7147): 941.

8. Van Loon B, Markkanen E, Hübscher U. Oxygen as a friend and enemy: how to combat the mutational potential of 8-oxo-guanine. DNA Repair. 2010; 9(6): 604-16.

9. Cheng KC, Cahill DS, Kasai H, Nishimura S, Loeb LA. 8-Hydroxyguanine, an abundant form of oxidative DNA damage, causes G---T and A----C substitutions. J Biol Chem. 1992; 267(1): 166-72.

10. Neeley WL, Essigmann JM. Mechanisms of formation, genotoxicity, and mutation of guanine oxidation products. Chem Res Toxicol. 2006; 19(4): 491-505.

11. Barnes DE, Lindahl T. Repair and genetic consequences of endogenous DNA base damage in mammalian cells. Annu Rev Genet. 2004; (38): 445-76.

12. Setoyama D, Ito R, Takagi Y, Sekiguchi M. Molecular actions of Escherichia coli MutT for control of spontaneous mutagenesis. Mutat Res. 2011; 707(1): 9-14.

13. Mildvan AS, Xia Z, Azurmendi HF, Saraswat V, Legler PM, Massiah MA, et al. Structures and mechanisms of Nudix hydrolases. Arch Biochem Biophys. 2005; 433(1): 129-43.

14. El-Sayed NM, Myler PJ, Bartholomeu DC, Nilsson D, Aggarwal G, Tran AN, et al. The genome sequence of Trypanosoma cruzi, etiologic agent of Chagas disease. Science. 2005; 309(5733): 409-15.

15. Passos-Silva DG, Rajão MA, Nascimento de Aguiar PH, Vieirada-Rocha JP, Machado CR, Furtado C. Overview of DNA Repair in Trypanosoma cruzi, Trypanosoma brucei, and Leishmania major. J Nucleic Acids. 2010; 2010: 840768.

16. Liarte DB, Murta SMF. Selection and phenotype characterization of potassium antimony tartrate-resistant populations of four New World Leishmania species. Parasitol Res. 2010; 107(1): 205-12. 
17. Robinson KA, Beverley SM. Improvements in transfection efficiency and tests of RNA interference (RNAi) approaches in the protozoan parasite Leishmania. Mol Biochem Parasitol. 2003; 128(2): 217-28.

18. Moreira DS, Neto RLM, Andrade JM, Santi AMM, Reis PG, Frézard F, et al. Molecular characterization of the MRPA transporter and antimony uptake in four New World Leishmania spp. susceptible and resistant to antimony. Int J Parasitol. 2013; 3: 143-53.

19. Huber W, Koella JC. A comparison of three methods of estimating EC50 in studies of drug resistance of malaria parasites. Acta Trop. 1993; 55(4): 257-61.

20. Aguiar PHN, Furtado C, Repolês BM, Ribeiro GA, Mendes IC, Peloso EF, et al. Oxidative stress and DNA lesions: the role of 8-oxoguanine lesions in Trypanosoma cruzi cell viability. PLoS Negl Trop Dis. 2013; 7(6): e2279.

21. Goyard S, Beverley SM. Blasticidin resistance: a new independent marker for stable transfection of Leishmania. Mol Biochem Parasitol. 2000; 108(2): 249-52.

22. Damasceno JD, Obonaga R, Silva GLA, Reis-Cunha JL, Duncan $\mathrm{SM}$, Bartholomeu DC, et al. Conditional genome engineering reveals canonical and divergent roles for the Husl component of the 9-1-1 complex in the maintenance of the plastic genome of Leishmania. Nucleic Acids Res. 2018; 46(22): 11835-46.

23. Silva MS, Muñoz PAM, Armelin HA, Elias MC. Differences in the detection of BrdU/EdU incorporation assays alter the calculation for G1, S, and G2 phases of the cell cycle in Trypanosomatids. J Eukaryot Microbiol. 2017; 64(6): 756-70.
24. Maki H, Sekiguchi M. MutT protein specifically hydrolyses a potent mutagenic substrate for DNA synthesis. Nature. 1992; 355(6357): 273.

25. Foti JJ, Devadoss B, Winkler JA, Collins JJ, Walker GC. Oxidation of the guanine nucleotide pool underlies cell death by bactericidal antibiotics. Science. 2012; 336(6079): 315-9.

26. Assis RR, Ibraim IC, Nogueira PM, Soares RP, Turco SJ. Glycoconjugates in New World species of Leishmania: polymorphisms in lipophosphoglycan and glycoinositolphospholipids and interaction with hosts. Biochim Biophys Acta. 2012; 1820(9): 1354-65.

27. Ibraim IC, Assis RR, Pessoa NL, Campos MA, Melo MN, Turco SJ, et al. Two biochemically distinct lipophosphoglycans from Leishmania braziliensis and Leishmania infantum trigger different innate immune responses in murine macrophages. Parasit Vectors. 2013; 6: 54.

28. Rajão MA, Furtado C, Alves CL, Passos-Silva DG, Moura MB, Schamber Reis BL, et al. Unveiling benznidazole's mechanism of action through overexpression of DNA repair proteins in Trypanosoma cruzi. Environ Mol Mutagen. 2014; 55(4): 309-21.

29. Andrade JM, Murta SMF. Functional analysis of cytosolic tryparedoxin peroxidase in antimony-resistant and-susceptible Leishmania braziliensis and Leishmania infantum lines. Parasit Vectors. 2014; 7(1): 406.

30. Tessarollo NG, Andrade JM, Moreira DDS, Murta SMF. Functional analysis of iron superoxide dismutase-A in wild-type and antimony-resistant Leishmania braziliensis and Leishmania infantum lines. Parasitol Int. 2015; 64(2): 125-9. 